\title{
Relações entre Intensidade da Doença, Refletância da Radiação Solar e Rendimento de Grãos no Patossistema Ferrugem da Folha de Trigo Embrapa 16
}

\author{
Erlei M. Reis ${ }^{1}$, Airton Leites ${ }^{2} \&$ Carlos A. Forcelini ${ }^{1}$ \\ ${ }^{1}$ Faculdade de Agronomia e Medicina Veterinária, Universidade de Passo Fundo, Cx. Postal 611, CEP 99001-970, \\ Passo Fundo, RS, e-mail: erleireis@tpo.com.br; ${ }^{2 B A S F, ~ C E P ~ 09851-550, ~ S a ̃ o ~ B e r n a n d o ~ d o ~ C a m p o, ~ S P ~}$
}

(Aceito para publicação em 06/11/2006)

Autor para correspondência: Erlei Melo Reis

REIS, E. M., LEITES, A. \& FORCELINI, C.A. Relações entre intensidade da ferrugem da folha, refletância da radiação solar e rendimento de grãos na cultura do trigo Embrapa 16. Fitopatologia Brasileira 31:447-454. 2006.

\begin{abstract}
RESUMO
Em experimentos com o cultivar de trigo Embrapa 16 conduzidos em Passo Fundo e Não-Me-Toque nas safras de 1999 e 2000 houve uma relação inversa entre a incidência foliar da ferrugem da folha do trigo, a severidade, o número de pústulas por centímetro quadrado e a área abaixo da curva de progresso da doença com o rendimento de grãos, e uma relação direta entre a refletância da radiação solar, na faixa de $810 \mathrm{~nm}$, com o rendimento de grãos. A refletância da radiação solar na faixa permitiu estimar o rendimento de grãos do trigo, a severidade da doença e o número de pústulas $\mathrm{cm}^{-2}$. As equações da função de dano com maior $\mathrm{R}^{2}$ obtidas pela análise de regressão permitem o cálculo do limiar de dano econômico (LDE) em diferentes estádios fenológicos da cultura. O LDE pode servir de critério indicador do momento para o controle da ferrugem da folha do trigo. Os danos causados pela doença atingiram um máximo de 43\%, com uma média de $40 \%$.
\end{abstract}

Palavras-chave adicionais: Fitopatometria, limiar de dano econômico, radiometria.

\begin{abstract}
Relationships between disease intensity, solar radiation reflectance and grain yield in the Embrapa 16 wheat leaf rust pathosystem

In field experiments with the Embrapa 16 wheat cultivar, carried out in Passo Fundo and Não-Me-Toque counties, in 1999 and 2000, the grain yield was negatively related to foliar rust incidence, foliar rust severity, the number of rust pustules per square centimeter, and the area under the disease progress curve. In contrast, there was a direct relationship between grain yield and the reflectance of solar radiation $(810 \mathrm{~nm})$ measured by a radiometer. The damage model equations obtained by regression analyses of disease and reflectance to yield were used to determine economic damage thresholds (EDTs) for the control of leaf rust in different plant growth stages. The yield reduction associated with leaf rust averaged $40 \%$, with a maximum of $43 \%$. The reflectance at $810 \mathrm{~nm}$ was related to grain yield, disease severity, and the number of pustules.
\end{abstract}

Additional keywords: Disease assessment, economic damage threshold, radiometry.

\section{INTRODUÇÃO}

O trigo (Triticum aestivum L.) é a cultura de inverno de maior expressão econômica no sul do Brasil, onde, na safra 2004, foram cultivados 2,76 milhões hectares, com produção de 5,85 milhões de toneladas e produtividade de $2.121 \mathrm{~kg} \mathrm{ha}^{-1}$. O consumo anual, no Brasil, é em torno de 10,5 milhões de toneladas (IBGE, 2005).

Devido às condições climáticas adversas, aliadas à suscetibilidade das cultivares e dependendo das práticas culturais, o trigo pode ter seu rendimento prejudicado pelo ataque de doenças causadas por fungos (Recomendações, 2000). Salienta-se a ferrugem da folha causada por Puccinia triticina Erikss. [sin. P. recondita f. sp. tritici D.M. Hend.; P. rubigo-vera (DC.) G. Wint.], por ser a doença mais comum desta cultura (Barcellos \& Ignazac, 1978; Samborsky, 1985; Reis et al., 2000).
Apesar de Barcellos \& Ignaczac (1978) terem demonstrado que os danos ocasionados pela ferrugem da folha podem chegar a 50\%, Picinini (1995) quantificou reduções de até $80 \%$ no rendimento de grãos no cultivar trigo BR 34. Reis et al. (2000) obtiveram coeficientes de dano para o cultivar Embrapa 16 variando de 10,5 a $18,7 \mathrm{~kg}$ ha $^{-1}$ para cada $1,0 \%$ de incidência foliar da ferrugem.

Alguns cultivares, como o Embrapa 16, são muito suscetíveis à ferrugem da folha, porém moderadamente resistentes a outras doenças, como o oídio. Nesses materiais suscetíveis, a ferrugem da folha é a principal causa de danos ao rendimento (Recomendações, 1999). Diante disso a aplicação de fungicidas nos órgãos áereos do trigo pode ser um fator de estabilização ou de aumento do rendimento, em níveis satisfatórios, para o triticultor, mesmo em anos com clima adverso à cultura (Recomendações, 1999).

Os objetivos deste trabalho foram a. gerar as 
funções de dano para o patossistema, P. triticina utilizando diferentes métodos fitopatométricos; b. quantificar os danos causados pela ferrugem da folha no cultivar trigo Embrapa 16; c. identificar o melhor critério para avaliar a intensidade da doença, relacionando o rendimento de grãos com a incidência foliar da doença, severidade, área abaixo da curva de progresso da doença e refletância da radiação solar, visando ao uso futuro em programas de manejo da doença, e d. estimar o rendimento de grãos em função da refletância da radiação solar.

\section{MATERIAL E MÉTODOS}

Fazem parte deste trabalho três experimentos conduzidos em dois locais e nas safras de trigo de 1999 e 2000, com o cultivar trigo Embrapa 16, suscetível a $P$. triticina e indicado para cultivo no Rio Grande do Sul (Recomendações, 1999).

\section{Experimento I - Não-Me-Toque (1999)}

Esteexperimentofoiconduzidonocampoexperimental da Cooperativa Tritícola Alto Jacuí Ltda, no município de Não-Me-Toque, RS, em área de rotação de culturas porque se objetivava menor ocorrência de manchas foliares (Reis et al., 1997). A correção da acidez do solo, o manejo de plantas daninhas em dessecação e em pós-emergência e a adubação de base e em cobertura foram realizados conforme indicações para a cultura (Recomendações, 1999). O tratamento de sementes foi efetuado com os fungicidas triadimenol ( $40 \mathrm{~g}$ i.a. $100 \mathrm{~kg}^{-1}$ de sementes), para o controle do oídio [Blumeria graminis (DC.) Speer f. sp. tritici] e iprodiona (100 g i.a.), para o controle de patógenos causadores de manchas foliares. Também foi realizado tratamento de sementes com o inseticida imidacloprida (50 g i.a.) visando ao controle de pulgões e corós. A semeadura foi realizada em 23/06/99, na densidade de 330 sementes aptas $\mathrm{m}^{-2}$.

No decorrer do desenvolvimento do experimento e tendo surgido o oídio, foram aplicados $2,0 \mathrm{~kg}$ de enxofre ha- ${ }^{-1}$ semanalmente, a partir do estádio de afilhamento em toda a área experimental.

O gradiente da intensidade da ferrugem foi gerado através da utilização de doses crescentes do fungicida sistêmico metconazole, conforme proposto por Sah \& MacKenzie (1987). Os tratamentos do ensaio foram: (1) testemunha sem controle, (2) aplicação de metconazole 45 g, (3) $54 \mathrm{~g}$, (4) $63 \mathrm{~g}$, (5) $72 \mathrm{~g}$, (6) $81 \mathrm{~g}$, (7) $90 \mathrm{~g}$ i.a. ha-1, todos com uma única aplicação, e (8) parcela-controle com a aplicação do fungicida na dose de $90 \mathrm{~g}$ i.a. ha ${ }^{-1}$ em quatro estádios fenológicos, portanto quatro aplicações.

A primeira aspersão do fungicida, nas unidades experimentais, foi realizada em 26/08/99, no surgimento das primeiras pústulas, no estádio de elongação do trigo. Utilizou-se um pulverizador costal manual de precisão, com pressão constante de $30 \mathrm{Lb} \mathrm{pol}^{-2}$ gerada por gás $\mathrm{CO}_{2}$, com barra de pulverização equipada com cinco pontas do tipo XR 110.02 espaçadas $0,50 \mathrm{~m}$ entre si e com volume de calda de $1701 \mathrm{ha}^{-1}$. Foram realizadas quatro aspersões do fungicida no tratamento 8 , nos estádios de afilhamento, emborrachamento, florescimento e enchimento de grãos (Zadoks et al., 1975).

O delineamento experimental foi em blocos ao acaso com quatro repetições. As unidades experimentais constaram de parcelas com 14 linhas espaçadas $17 \mathrm{~cm}$ entre si, com $6 \mathrm{~m}$ de comprimento $\left(14,28 \mathrm{~m}^{2}\right)$.

As avaliações da intensidade da ferrugem da folha foram realizadas com base na incidência foliar (Nutter et al., 1993), severidade (Percentagem da área foliar afetada atual sem uso de escala) e número de pústulas $\mathrm{cm}^{-2}$ na área central da folha. Coletaram-se dez afilhos por unidade experimental, de preferência nas três primeiras linhas de cada lado das unidades experimentais. Em laboratório, destacaramse as folhas verdes, expandidas e não senescentes. Para a incidência, separaram-se as folhas com no mínimo uma pústula esporulante das sadias, estabelecendo-se o percentual de folhas infectadas (Reis, 1994). Na mesma amostra, foi avaliada a severidade da ferrugem da folha. Antes das avaliações da severidade, utilizou-se o programa desenvolvido por Tomerlin \& Howell (1988) para treinamento visual do avaliador. A contagem do número de pústulas $\mathrm{cm}^{-2}$ foi realizada com auxílio de uma lupa de mão, que limitava o campo visual em um $\mathrm{cm}^{-2}$ na área central da folha. As avaliações foram realizadas semanalmente, nos seguintes estádios fenológicos: afilhamento, elongação, emborrachamento, espigamento, florescimento e enchimento de grãos (Zadoks et al., 1975).

O rendimento de grãos foi determinado colhendo-se as plantas em 5,0 metros das oito linhas centrais das unidades experimentais, em uma área útil de $6,8 \mathrm{~m}^{2}$, com o auxílio de uma colhedora de parcelas Wintersteiger, em 09/11/99. Após a colheita, os grãos passaram pelos processos de secagem, limpeza e pesagem, sendo a umidade de grãos corrigida para o valor de $13 \%$. O cálculo do dano causado pela ferrugem da folha foi expresso em percentagem, pela diferença de produção entre as parcelas com diferentes níveis de doença e as parcelas sadias.

Os dados foram submetidos à análise variância. No caso do teste $\mathrm{F}$ significativo foi ajustado pelo modelo de regressão polinomial, utilizando-se o programa PlotIT for Windows (Scientific Programming Enterprises, Haslett, MI).

A partir das equações das funções de dano obtidas por análise de regressão dos dados, contendo os coeficientes de dano, calculou-se o limiar de dano econômico (LDE) como critério indicador do momento para a aplicação econômica de fungicidas visando ao controle químico da ferrugem da folha em diferentes estádios fenológicos da cultura do trigo (Reis et al., 2001).

\section{Experimento II - Passo Fundo (1999)}

O experimento foi conduzido no campo experimental da Faculdade de Agronomia e Medicina Veterinária da Universidade de Passo Fundo, RS, no ano agrícola de 1999. 
As unidades experimentais, o cultivar de trigo, o tratamento de sementes, a densidade de semeadura, a adubação, o manejo de plantas daninhas foram os mesmos do Experimento I (Recomendações, 1999). A primeira aspersão do fungicida, foi realizada no dia 28/08/99, no surgimento das primeiras pústulas, com o mesmo equipamento do Experimento I, estando o trigo no estádio de elongação. Os demais procedimentos relativos à colheita, processamento dos grãos e cálculo do rendimento foram semelhantes ao Experimento anterior.

As avaliações da intensidade da ferrugem da folha foram semelhantes às do Experimento I, com exceção do sensoriamento remoto, no qual as leituras de refletância da radiação solar foram realizadas utilizando-se um radiômetro de múltiplo espectro portátil CropScan, modelo MSR87, que quantificou a porcentagem de radiação solar refletida pelo dossel em oito comprimentos de onda $(460,510,560,610$, $660,710,760$ e $810 \mathrm{~nm}$ ). O sensor foi montado em uma barra e um coletor de dados conectado, gravando todos os dados automaticamente. Durante a leitura, a barra permaneceu sob um ângulo de $45^{\circ}$, com o sensor a uma altura de $1,60 \mathrm{~m}$ em relação ao solo. Foram realizadas três leituras em cada parcela sendo a área avaliada correspondente a um círculo com diâmetro igual à metade da altura do sensor centralizado no início, metade e final das parcelas. A avaliação de sensoriamento remoto foi realizada no estádio de enchimento de grãos, sempre pela manhã, por volta das 10 horas.

\section{Experimento III - Passo Fundo (2000)}

O experimento foi conduzido no campo experimental da Faculdade de Agronomia e Medicina Veterinária da Universidade de Passo Fundo, RS. Sendo o cultivar de trigo, a adubação e os demais tratos culturais os mesmos dos experimentos anteriores.

Objetivando garantir o inóculo na área experimental, foram feitas inoculações artificiais no experimento com uredosporos da Raça B 44 de P. triticina (Barcellos, informação pessoal), no afilhamento e no emborrachamento do trigo. A inoculação foi feita pulverizando-se uma suspensão de concentração não determinada de esporos, sobre as plantas, no estádio de afilhamento, após o pôr-do-sol.

O gradiente da intensidade da doença foi gerado através da utilização de doses crescentes do fungicida metconazole, conforme proposto por Sah \& MacKenzie (1987). Os tratamentos utilizados na execução do ensaio foram os seguintes: (1) testemunha sem controle, (2) metconazole $9 \mathrm{~g}$, (3) $18 \mathrm{~g}$, (4) $27 \mathrm{~g}$, (5) $36 \mathrm{~g}$, (6) $45 \mathrm{~g}$, (7) $54 \mathrm{~g}$, (8) $63 \mathrm{~g}$, (9) $72 \mathrm{~g}$, (10) $81 \mathrm{~g}$, (11) $90 \mathrm{~g}$ i.a. ha ${ }^{-1}$, todos aplicados uma única vez, e (12) parcela-controle sem doença envolvendo quatro aplicações do fungicida a intervalos de 15 dias. A primeira aspersão do fungicida foi realizada em 22/09/2000, no surgimento das primeiras pústulas, utilizando-se o mesmo equipamento dos experimentos anteriores. As mesmas avaliações patométricas dos experimentos anteriores foram procedidas neste ensaio.

Utilizando-se a equação de Munford \& Norton (1984), modificada e aplicada para doenças (Reis et al., 2001), calculou- se o LDE com as funções de dano obtidas para todos os critérios patométricos utilizados. Dessa maneira, com base nas equações de função de dano obtidas e representadas nas Figuras 1 B, 2 B, 3 B, 4 B, 5 A e 5B, calculou-se o LDE utilizando o CD de cada equação considerandos-e o custo de controle de US\$ $31.00 \mathrm{ha}^{-1}$ (Picinini et al., 1996), US\$ $120.00 \mathrm{t}^{-1}$ de trigo e 95\% de eficácia do fungicida metconazole.

\section{RESULTADOS E DISCUSSÃO}

\section{Experimento I - Não-Me-Toque (1999)}

A incidência da ferrugem na folha, a severidade, o número de pústulas $\mathrm{cm}^{-2} \mathrm{e}$ a área abaixo da curva de progresso da doença, relacionaram entre si e com o rendimento de grãos do cultivar Embrapa 16 e foram representadas por equações quadráticas, onde "R" representa o rendimento de grãos; "I" a incidência da ferrugem da folha; "S" a severidade; "NP" o número de pústulas. $\mathrm{cm}^{-2} \mathrm{e}$ "A" a área abaixo da curva de progresso da doença.

As relações entre incidência foliar e rendimento de grãos apresentaram equações com $\mathrm{R}^{2}$ entre 0,09 e 0,57 (Figura $\left.1 \mathrm{~A}, \mathrm{R}^{2}=0,48\right)$. Quando se confrontou a severidade com o rendimento, os coeficientes de determinação $\left(\mathrm{R}^{2}\right)$ variaram de 0,51 a 0,64 (Figura $2 \mathrm{~A}, \mathrm{R}^{2}=0,64$ ). O número de pústulas em relação ao rendimento apresentou $\mathrm{R}^{2}=0,58$ (Figura $4 \mathrm{~A}$ ). Neste experimento, foi possível contar até 84 pústulas $\mathrm{cm}^{-2}$. Para a AACPD e rendimento, $\mathrm{R}^{2}=0,56$ (Figura $3 \mathrm{~A}$ ). Por causa dos baixos coeficientes de determinação das equações na cultivar Embrapa 16, nenhuma das características foi escolhida para estimar o rendimento de grãos e calcular os LDE para ferrugem da folha do trigo.

Não houve boa correlação entre incidência e severidade. No espigamento, o $\mathrm{R}^{2}$ da equação da função de dano foi de 0,63 (Figura 1D). Ainda no estádio de espigamento, a equação que representa a relação entre número de pústulas e incidência apresentou $\mathrm{R}^{2}=0,80$ (Figura $4 \mathrm{D}$ ). $\mathrm{O} \mathrm{R}^{2}$ da equação que representa as relações entre incidência e número de pústulas decresceu com o aumento da incidência.

Neste experimento, o rendimento de grãos variou de $1.341,7 \mathrm{~kg} \mathrm{ha}^{-1}$ na testemunha a $2.298 \mathrm{~kg} \mathrm{ha}^{-1}$ na parcela controle, o que representou dano de $42 \%$ causado por $P$. triticina.

\section{Experimento II - Passo Fundo (1999)}

As relações entre a incidência foliar, severidade, número de pústulas, refletância, área abaixo da curva de progresso da doença (AACPD) e rendimento de grãos da cultivar Embrapa 16 foram representadas por equações quadráticas (Figuras 1, 2, 3, 4 e 5).

Houve relação inversa entre a incidência foliar e o rendimento, sendo que as equações da função de dano apresentaram coeficiente de determinação $\left(\mathrm{R}^{2}\right)$ entre $0,64 \mathrm{e}$ 0,78 (Figura $1 \mathrm{~B}, \mathrm{R}^{2}=0,78$ ) nas avaliações realizadas antes de a incidência atingir $100 \%$ na testemunha, o que aconteceu no enchimento de grãos do trigo. No estádio de florescimento, o coeficiente de dano (CD) foi de 7,96 $\mathrm{kg} \mathrm{ha}^{-1}$, o que significa que, 

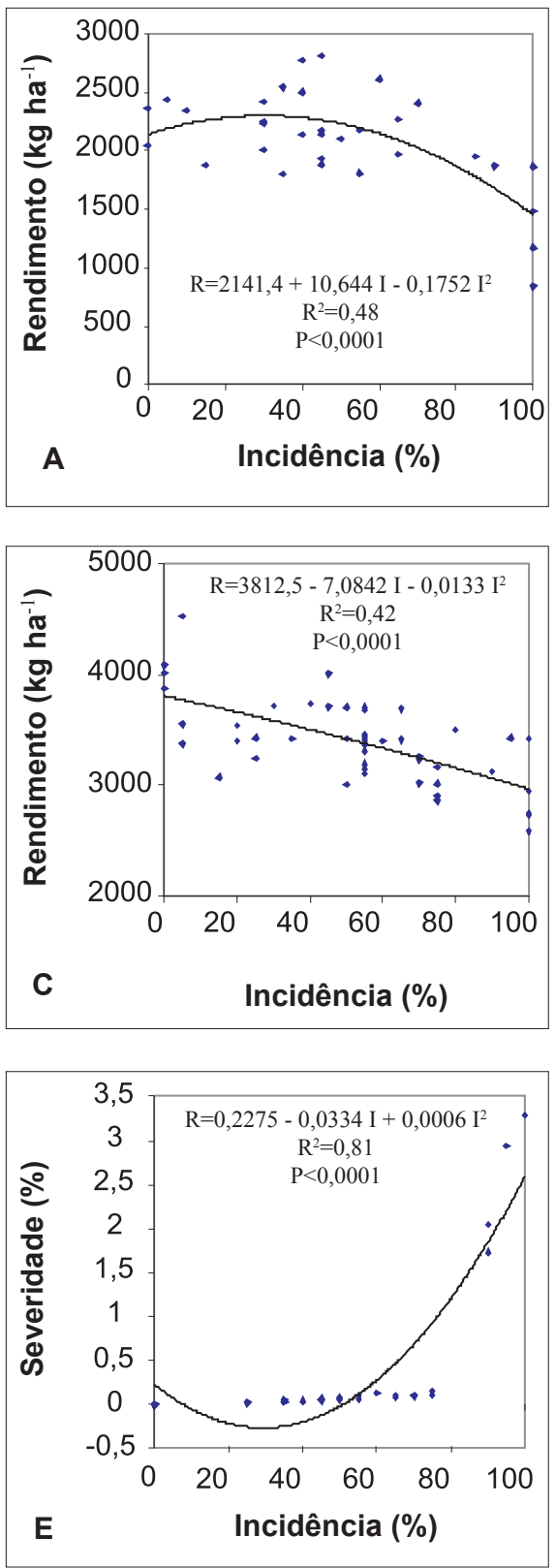
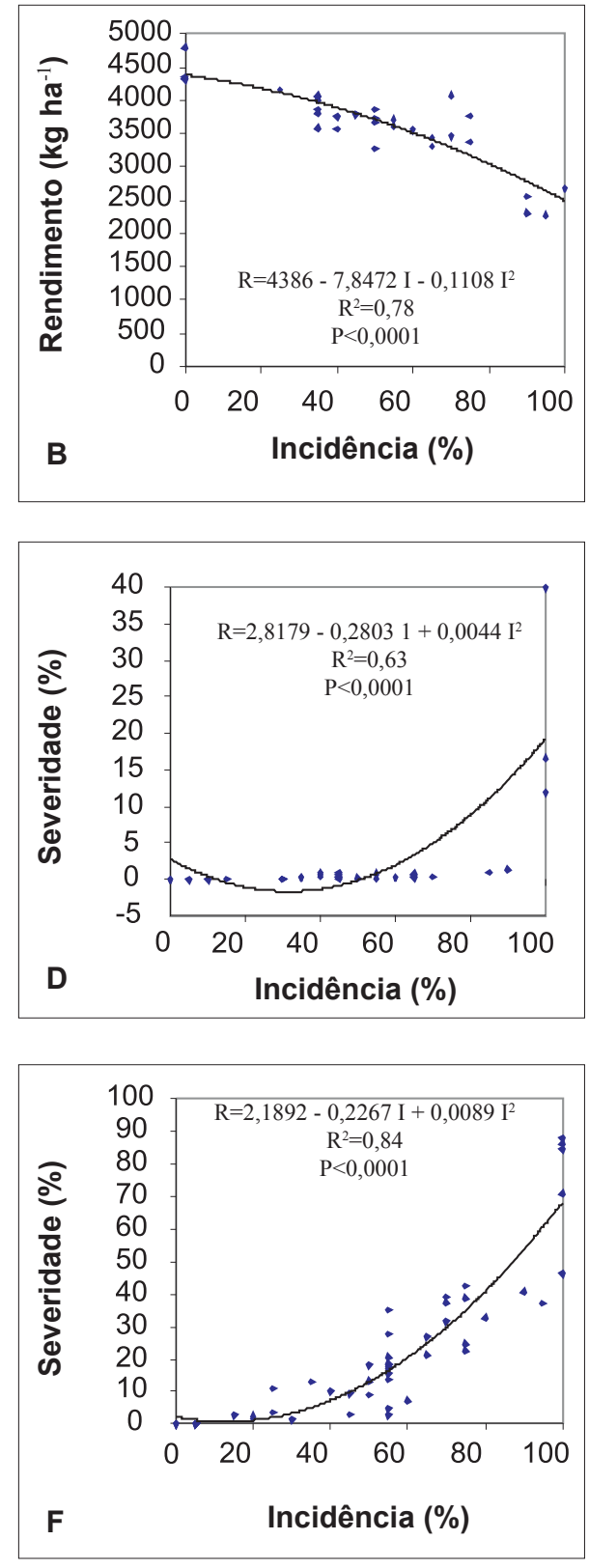

FIG. 1 - Relações entre: A. rendimento de grãos de trigo e incidência da ferrugem da folha no estádio de espigamento (NãoMe-Toque);;B. rendimento de grãos e incidência no estádio de florescimento (Passo Fundo/99), C. rendimento de grãos e incidência no estádio de florescimento (Passo Fundo/00); D. severidade e incidência no estádio de espigamento (Não-Me-Toque); E. severidade e incidência no estádio de florescimento (Passo Fundo/99); F. severidade e incidência no estádio de florescimento (Passo Fundo/00) Cultivar Embrapa 16. para $1 \%$ de incidência da ferrugem da folha, houve uma redução no rendimento de grãos de $7,96 \mathrm{~kg} \mathrm{ha}^{-1}$.

Segundo a equação de Munford \& Norton (1984), o CD indica o dano $\left(\mathrm{kg} \mathrm{ha}^{-1}\right)$ causado para cada $1 \%$ de incidência da doença. Com uma incidência de 50\% no estádio de florescimento, o rendimento seria de $3.716,6 \mathrm{~kg} \mathrm{ha}^{-1}$, segundo a equação da função de dano. Na avaliação realizada no estádio de enchimento de grãos do trigo, quando a incidência foi de $100 \%$ na testemunha e em alguns tratamentos, esta não foi uma boa característica para explicar o rendimento.

A relação entre severidade e rendimento foi inversa, com $\mathrm{R}^{2}=0,65$ na fase de elongação, o que é explicado pela baixa severidade nas primeiras avaliações, até $\mathrm{R}^{2}=0,78$ no enchimento de grãos (Figura 2B). No estádio de enchimento de grãos, o CD foi de $193,4 \mathrm{~kg} \mathrm{ha-1}$.
O número de pústulas $\mathrm{cm}^{-2}$ mostrou as melhores correlações com o rendimento de grãos, sendo que o $\mathrm{R}^{2}$ das equações variou de 0,66 a 0,91 . No estádio de enchimento de grãos, a relação entre o número de pústulas $\mathrm{cm}^{-2}$ apresentou relação inversa com o rendimento, com $\mathrm{CD}=60$ $\mathrm{kg} \mathrm{ha}^{-1}$ (Figura $4 \mathrm{~B}$ ).

Em relação às avaliações realizadas com a refletância da radiação solar pela área foliar sadia, os comprimentos de onda na faixa do infravermelho-próximo apresentaram as melhores correlações com o rendimento, com destaque para a faixa de 810 $\mathrm{nm}(\mathrm{r}=0,91)$. $\mathrm{O}$ índice de vegetação (IR) e a diferença normalizada (DN), recomendados por Nilsson (1995) para uso em trabalhos de fitopatologia, não apresentaram vantagens na interpretação dos resultados sobre a faixa de $810 \mathrm{~nm}$. Em virtude desse fato, esse comprimento de onda foi utilizado isoladamente para analisar 
Relações entre intensidade da doença, refletância da radiação solar...
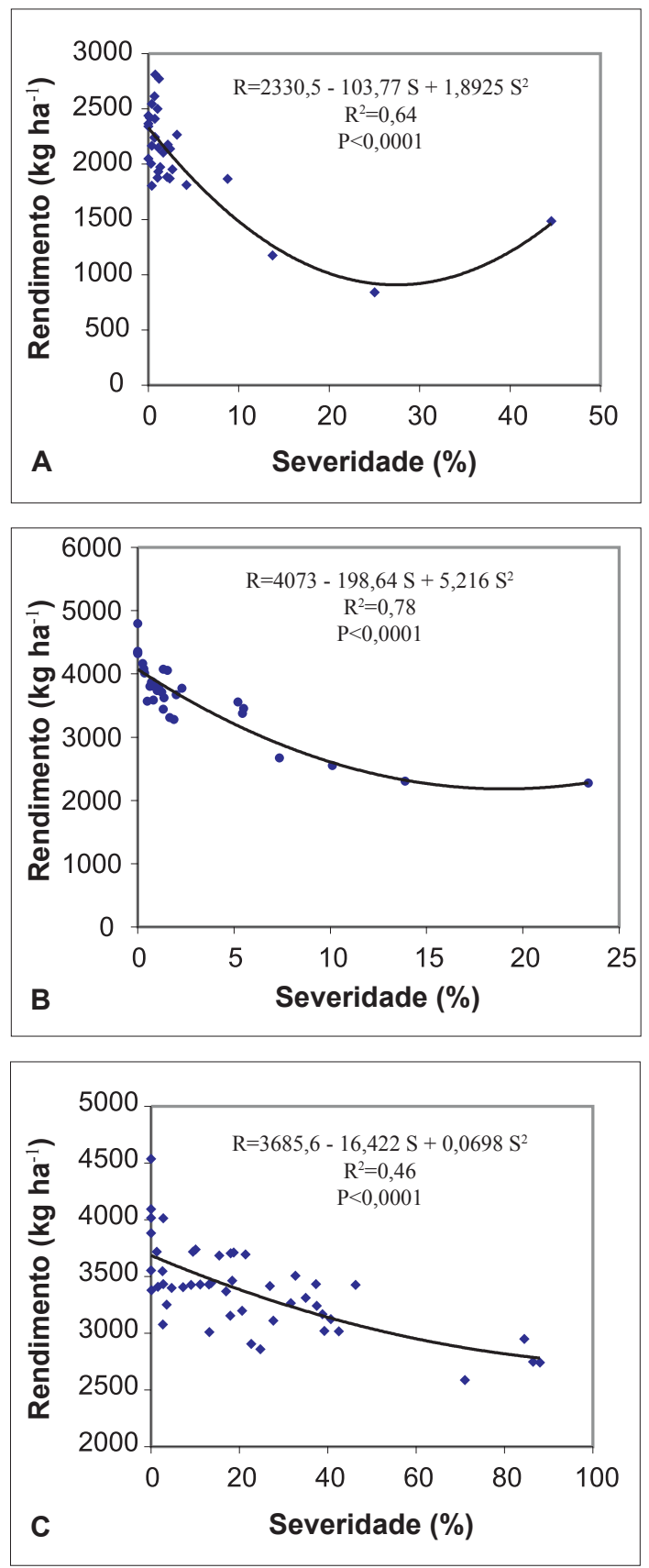

FIG. 2 - Relações entre: A. rendimento de grãos de trigo e severidade da ferrugem da folha no estádio de florescimento (NãoMe-Toque); B. rendimento e severidade no estádio de enchimento de grãos (PassoFundo/99); C. rendimento e severidade no estádio de florescimento (Passo Fundo/00) - Cultivar Embrapa 16.

os dados. O comportamento do rendimento de grãos com relação à refletância em infravermelho na faixa de $810 \mathrm{~nm}$ mostrou $\mathrm{R}^{2}$ de 0,88 , quando a avaliação ocorreu no estádio de enchimento de grãos (Figura 5A). Essa relação direta apresentou $\mathrm{CD}=650,4$, deduzindo-se que $1 \%$ de refletância na faixa de $810 \mathrm{~nm}$, no enchimento de grãos da cultivar Embrapa 16, corresponderia a um rendimento de $650,4 \mathrm{~kg}$ $\mathrm{ha}^{-1}$. Nesse estádio a refletância de $25 \%$ corresponderia a
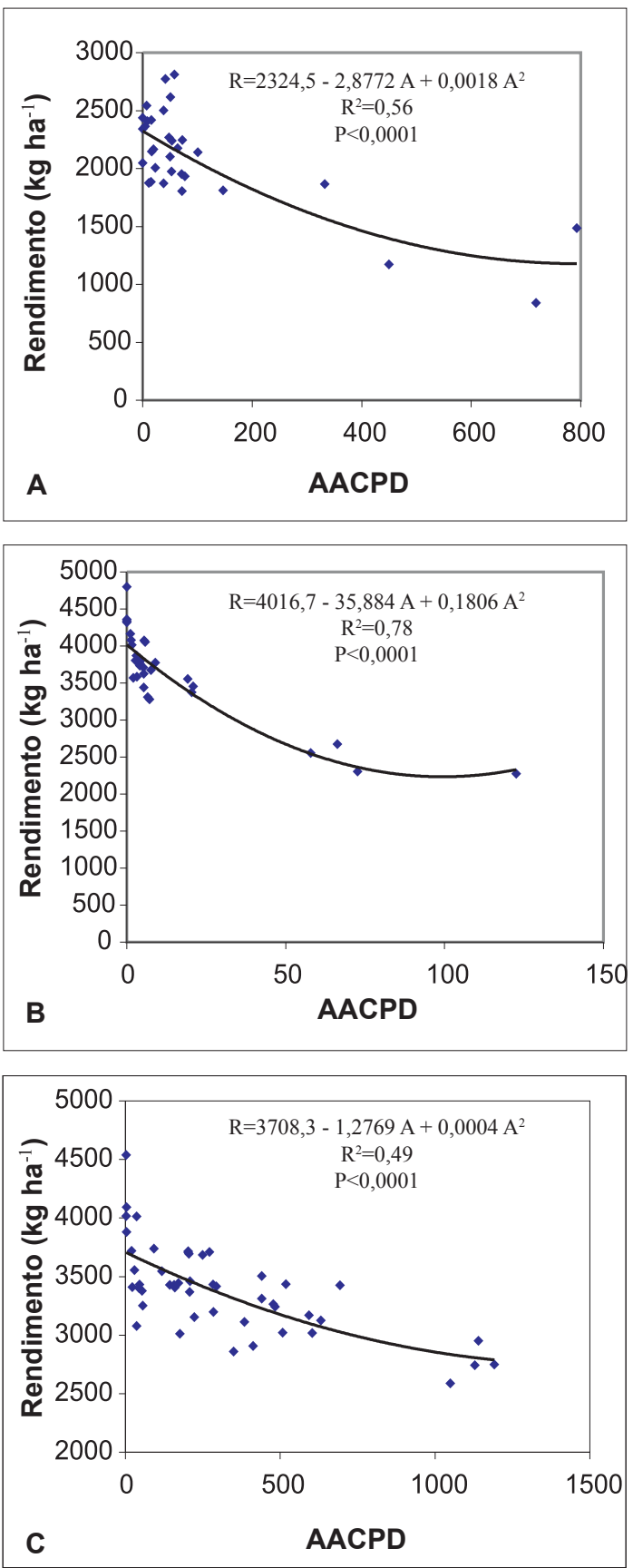

FIG. 3 - Relações entre: A. rendimento de grãos de trigo e AACPD no estádio de enchimento de grãos (Não-Me-Toque); B. rendimento e AACPD de grãos no estádio de enchimento de grãos (Passo Fundo/99); C. rendimento e AACPD no estádio de enchimento de grãos (Passo Fundo/00) - Cultivar Embrapa 16.

um rendimento de $4.470,15 \mathrm{~kg} \mathrm{ha}^{-1}$.

Observou-se que o critério de avaliação pelo número de pústulas $\mathrm{cm}^{-2}$ forneceu resultados mais precisos, porém concorda-se com Bergamin Filho \& Amorim (1996) que a contagem de lesões só é exeqüível em trabalhos experimentais, quando se requer alta precisão devido as avaliações trabalhosas e que demandam muito tempo. Já a avaliação realizada com o radiômetro de múltiplo espectro mostrou que $88 \%$ da redução 
do rendimento pode ser explicada pela redução da refletância da radiação solar, na faixa de $810 \mathrm{~nm}$, causada pela infecção por $P$. triticina. Este seria um método com potencial de uso prático para trabalhos experimentais de campo e na avaliação da doença em lavouras comerciais.

A equação que relaciona a área abaixo da curva de progresso da doença (AACPD) com o rendimento de grãos apresentou um $\mathrm{R}^{2}=0,78$ (Figura 3B), o que concorda com alguns autores, como Bergamin Filho \& Amorim (1996), que preconizam ser essa uma maneira eficaz de se estimar o rendimento, pois leva em conta o estresse que a cultura sofreu durante vários estádios de desenvolvimento. Nesse caso, o CD da relação inversa entre AACPD e o rendimento foi de 35,7 unidades, significando que, para uma unidade de AACPD, ocorreu uma redução de $35,7 \mathrm{~kg} \mathrm{ha}^{-1}$ no rendimento de grãos.

Comparando-se o uso em lavouras comerciais dos valores da AACPD com a incidência e severidade, a AACPD não tem a mesma praticabilidade para quantificar a doença $\mathrm{e}$ tomar uma decisão em relação ao momento da aplicação de fungicidas visando ao controle da doença alvo deste estudo. Para o cultivar trigo Embrapa 16, o LDE correspondeu a 30,8 $\%$ de incidência foliar da ferrugem no florescimento, a $1,3 \%$ de severidade no enchimento de grãos, a 4,1 pústulas $\mathrm{cm}^{-2}$ no enchimento de grãos, a $0,4 \%$ de refletância na faixa de $810 \mathrm{~nm}$ no enchimento de grãos e a 6,9 unidades de AACPD.

No estádio de florescimento do trigo, houve uma relação entre a incidência e severidade da doença, apresentando esta relação $\mathrm{R}^{2}=0,81$ (Figura 1E). Esse fato concorda com Amorim (1995), que relata ser a incidência uma característica útil para avaliar a maioria das doenças quando a epidemia está em sua fase inicial, ocasião em que pode ser correlacionada com a severidade. A incidência de $1 \%$ correspondeu à severidade de $0,2 \%$; incidência de $100 \%$ correspondeu a $2,9 \%$ de severidade. A correlação entre severidade e incidência da ferrugem da folha do trigo foi estabelecida por Reis et al. (1996), os quais demonstraram que a severidade de $5 \%$ correspondeu à incidência de $76,5 \%$.

No florescimento do trigo, a relação entre o número de pústulas e a incidência apresentou $\mathrm{R}^{2}=0,78$ (Figura 4 E). O coeficiente de determinação foi menor no estádio de enchimento de grãos em razão do aumento da incidência para $100 \%$. Neste caso, uma pústula $\mathrm{cm}^{-2}$ correspondeu a $49 \%$ de incidência.

Havendo relação entre a incidência e a severidade em um patossistema, pode optar-se, em avaliações de lavouras comerciais, pela incidência, variável objetiva e ainda demanda menos tempo na sua quantificação (Reis et al., 1996)

Quanto maior foi a severidade da doença maior a refletância da radiação solar nos comprimentos de onda de $460,510,560,610,660$ e $710 \mathrm{~nm}$ e menor em 760 e $810 \mathrm{~nm}$. O mesmo comportamento foi observado por Canteri (1998) em experimentos conduzidos na cultura do feijoeiro. Em avaliação realizada no enchimento de grãos do trigo, observaram-se relações significativas entre refletância e incidência (Figura 5 C), refletância e severidade (Figura $5 \mathrm{E}$ ), refletância e número de pústulas (Figura $5 \mathrm{G}$ ) e refletância e AACPD (Figura 5 I). Portanto, para essa cultivar e nas condições observadas pode-se estimar esses critérios patométricos, na fase de enchimento de grãos
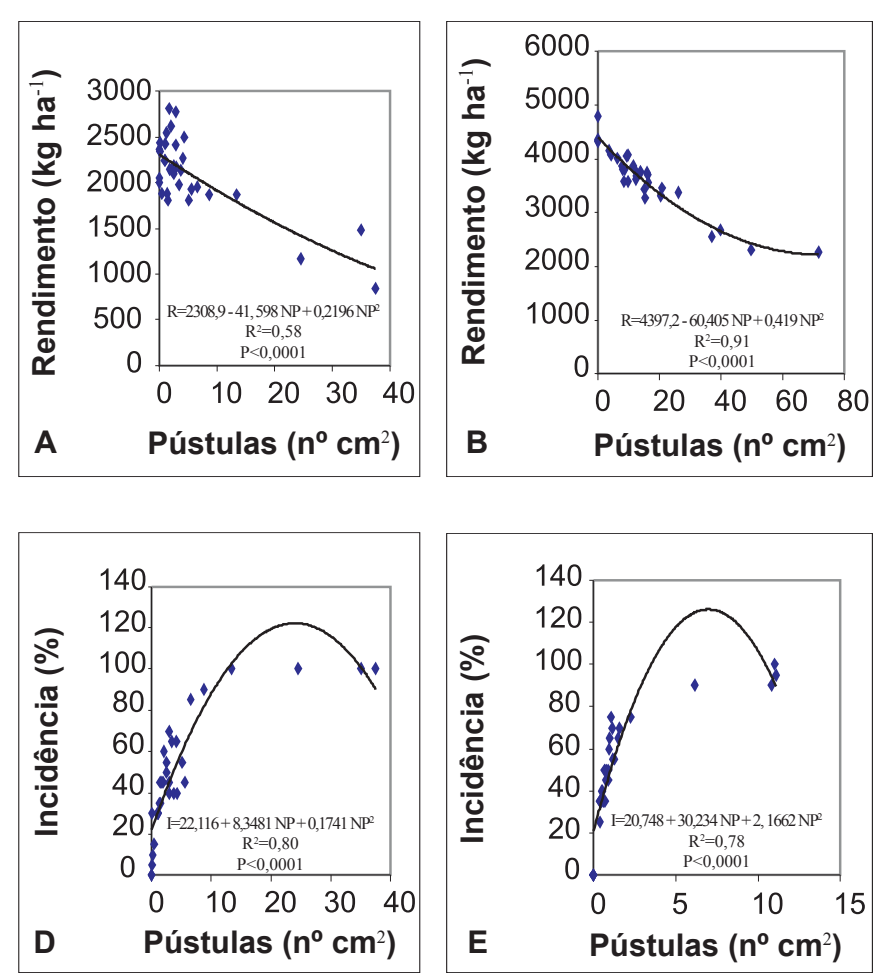
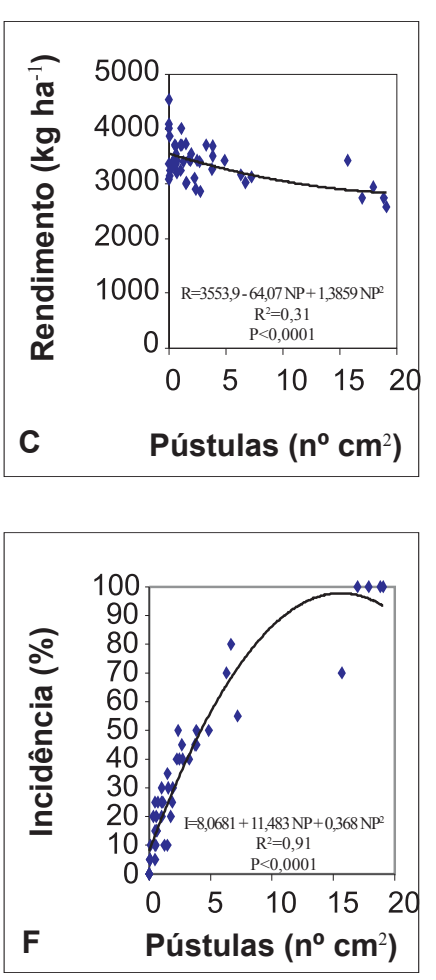

FIG. 4 - Relações entre: A. rendimento de grãos de trigo e número de pústulas da ferrugem dafolhano estádio de espigamento (Não-Me-Toque); B. rendimento de grãos e número de pústulas no estádio de enchimento de grãos (Passo Fundo/99); C. rendimento e número de pústulas no estádio de espigamento (Passo Fundo/00); D. número de pústulas e incidência no estádio de espigamento(Não-Me-Toque); E. número de pústulas e incidência no estádio de florescimento (Passo Fundo/99); F. número de pústulas e incidência no estádio de espigamento (Passo Fundo/00) -Cultivar Embrapa 16. 
do trigo, através da utilização do radiômetro de múltiplo espectro. A refletância de $20 \%$ correspondeu à incidência de $95,8 \%$, à severidade de $1,2 \%$, a 10,9 pústulas $\mathrm{cm}^{-2}$ e a 3,7 unidades de AACPD.

Neste experimento, o rendimento de grãos variou de $2.451,6 \mathrm{~kg} \mathrm{ha}^{-1}$ na testemunha a $4.453 \mathrm{~kg} \mathrm{ha}^{-1}$ na parcela controle, livre de doença. Isso representou dano de $45 \%$ causado por $P$.triticina.

\section{Experimento III - Passo Fundo (2000)}

Nas relações entre as características avaliadas e o rendimento de grãos, não foi ajustada equação com $\mathrm{R}^{2}$ superior a 0,52 (Figuras $1 \mathrm{C}, 2 \mathrm{C}, 3 \mathrm{C}, 4 \mathrm{C}$ e $5 \mathrm{~B}$ ). O maior coeficiente de determinação foi obtido utilizando-se a técnica de sensoriamento remoto, que se mostrou útil quando da ocorrência de um patossistema múltiplo, como foi o caso deste experimento, que apresentou a presença de manchas foliares.
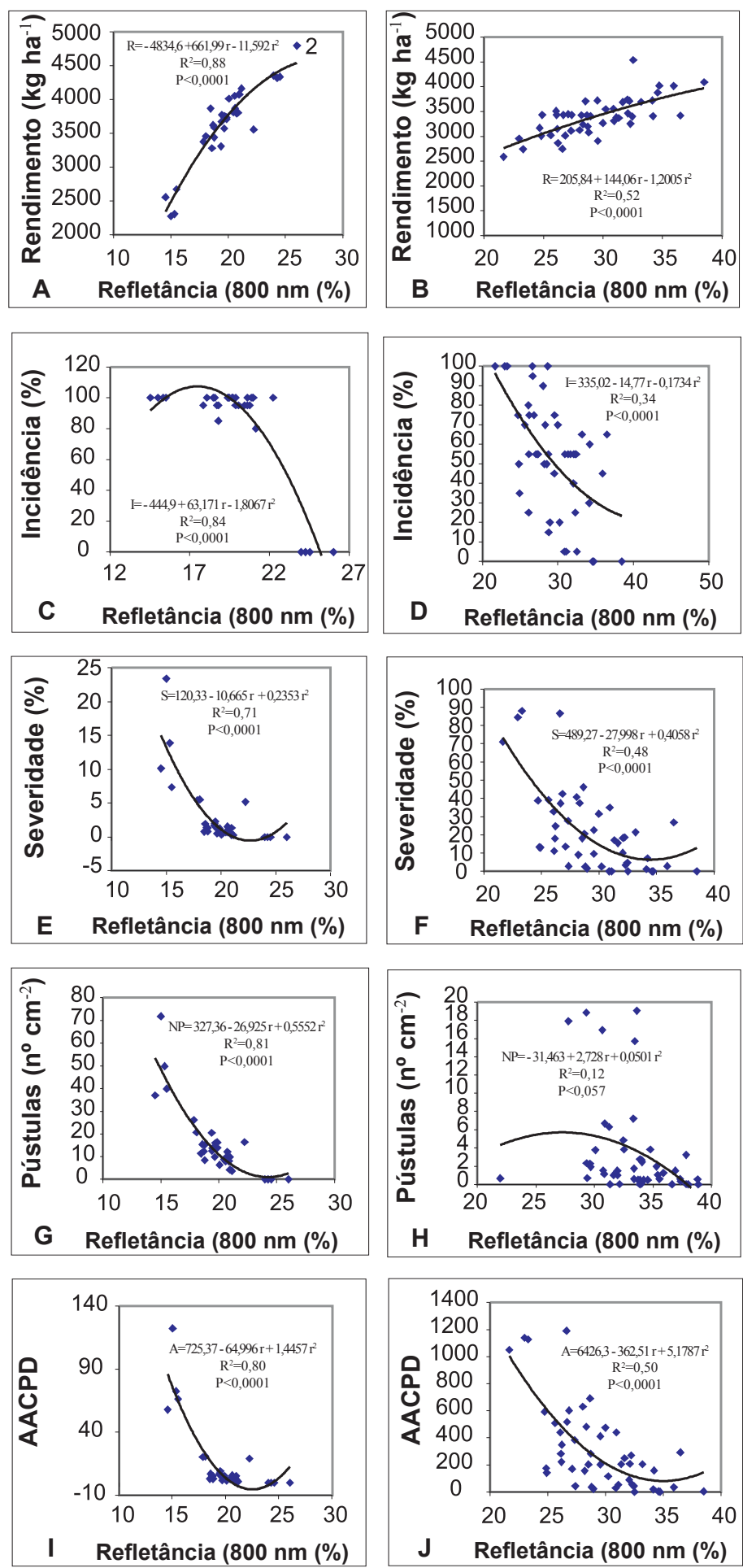
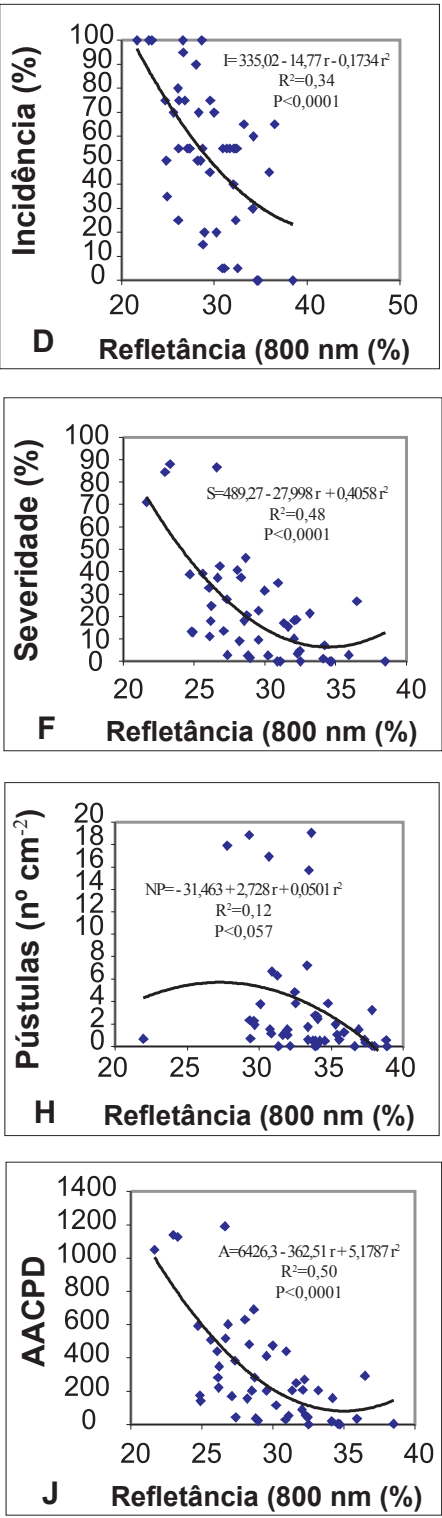

FIG. 5 - Relações entre: A. refletância e rendimento no estádio de enchimento de grãos (Passo Fundo/99); B. refletância e rendimento no estádio de florescimento (Passo Fundo/00); C. refletância e incidência no estádio de enchimento de grãos (Passo Fundo/99); D. refletância e incidência no estádio de florescimento (P. Fundo/00); E. refletância e severidade no estádio de enchimento de grãos (Passo Fundo/99); F. refletância e severidade no estádiodeflorescimento(PassoFundo/00); G. refletância e número de pústulas no estádio de enchimento de grãos (Passo Fundo/99); H. refletância e número de pústulas no estádio de espigamento (Passo Fundo/00); I. refletância e AACPD no estádio de enchimento de grãos (Passo Fundo/99); J. refletância e AACPD no estádio de enchimento de grãos (Passo Fundo/00) - Cultivar Embrapa 16. 
Para o cultivar trigo Embrapa 16, o LDE correspondeu a 1,7 \% de refletância na faixa de $810 \mathrm{~nm}$ no estádio de florescimento. Neste experimento, o rendimento de grãos variou de $2.757 \mathrm{~kg}$ ha $^{-1}$ na testemunha a $4.132 \mathrm{~kg} \mathrm{ha}^{-1}$ na parcela-controle, o que representou dano de $33 \%$ causado por P. triticina.

A equação que representa a relação entre incidência e severidade no estádio de florescimento apresentou $\mathrm{R}^{2}=0,84$ (Figura 1F). Neste estádio da cultura, 18\% de incidência corresponderam a $1 \%$ de severidade e $35 \%$ de incidência, a $5 \%$ de severidade. A relação entre o número de pústulas e a incidência no espigamento apresentou $\mathrm{R}^{2}=0,91$ (Figura 4F). Nesse estádio de desenvolvimento da cultura, 1,0 pústula $\mathrm{cm}^{-}$ ${ }^{2}$ correspondeu a $0,5 \%$ de severidade. Pode-se concluir que houve relação inversa entre a incidência foliar, a severidade, $o$ número de pústulas por centímetro quadrado, a AACPD com o rendimento de grãos e uma relação direta entre a refletância da radiação solar, na faixa de $810 \mathrm{~nm}$, com o rendimento de grãos. As equações de dano com maior $\mathrm{R}^{2}$ obtidas pela análise de regressão permitiram o cálculo do LDE em diferentes estádios fenológicos da cultura, o que pode servir como critério indicador do momento para se proceder a aplicação de fungicidas visando ao controle econômico da ferrugem da folha do trigo.

Os danos causados pela ferrugem da folha do trigo atingiram, nos experimentos, um máximo de $43 \%$. A refletância da radiação solar na faixa de $810 \mathrm{~nm}$ permitiu estimar o rendimento de grãos do trigo $\left(\mathrm{R}^{2}=0,88\right)$, a severidade da doença $\left(\mathrm{R}^{2}=0,71\right)$ e o número de pústulas $\mathrm{cm}^{-2}\left(\mathrm{R}^{2}=0,81\right)$. Sugere-se, com base nos dados aqui obtidos, que se utilize em avaliações patométricas em pesquisa, a densidade de urédias e nas de campo a incidência foliar por serem objetivos e mais precisos.

\section{REFERÊNCIAS BIBLIOGRÁFICAS}

AMORIM, L. Avaliação de doenças. In: Bergamin Filho, A. Kimati, H. \& Amorim, L. (Eds.) Manual de Fitopatologia. Vol. 1. Princípios e Conceitos. São Paulo SP. Ceres. 1995. pp. 234-235.

BARCELLOS, A.L. \& IGNACZAC, J.C. Efeito da ferrugem da folha em diferentes estádios de desenvolvimento do trigo. In: Reunião Anual Conjunta de Pesquisa de Trigo, 10, Porto Alegre, 1978. Solos e Técnicas Culturais, Economia e Sanidade. Passo Fundo, Centro Nacional de Pesquisa de Trigo. 1978. pp. 212-219.

BERGAMIN FILHO, A. \& AMORIM, L. Doenças de plantas tropicais: Epidemiologia e controle econômico. São Paulo SP. Ceres. 1996.

CANTERI, M.G. Uso de medidas da área foliar sadia e refletância no manejo da mancha angular do feijoeiro. Tese de Doutorado. Piracicaba SP. ESALQ, Universidade de São Paulo. 1998.

IBGE. Indicadores estatísticos para agricultura. 2005 Online. http:// www.ibge.gov.br/ibge/estatística/indicadores/agropecuaria.
MUNFORD, J.D. \& NORTON, G.A. Economics of decision making in pest management. Annual Review Entomology 29:157-174. 1984.

NILSSON, H.E. Remote sensing and image analysis in plant pathology. Annual Review of Phytopathology 33:489-527. 1995.

NUTTER, F.W., TENG, P.S. \& ROYER, M.H. Terms and concepts for yield, crop loss, and disease thresholds. Plant Disease 77:211-215. 1993.

PICININI, E.C. Estratégias no manejo de enfermidades e proteção química de cereais de inverno. In: Kohli, M.M., Anone, J.G. \& García, R. (Eds.) Curso de manejo de enfermedades del trigo. CIMMYT, Estación Experimental Agropecuaria INTA Pergamino, Buenos Aires, Argentina. 1995. pp. 35-52.

PICININI, E.C., FERNANDES, J.M.C., IGNACZAC, J.C. \& AMBROSI, I. Impacto econômico do uso do fungicida propiconazole na cultura do trigo (Triticum aestivum). Fitopatologia Brasileira 21:362-368. 1996.

RECOMENDAÇÕES. Reunião da Comissão Sul-Brasileira de Pesquisa de Trigo, 31, 1999, Passo Fundo, RS. Recomendação da Comissão Sul-Brasileira de Pesquisa de Trigo-1999. Passo Fundo, 1999. 86p.

RECOMENDAÇÕES. Reunião da Comissão Sul-Brasileira de Pesquisa de Trigo, 32, 2000, Cruz Alta, RS. Recomendação da Comissão Sul-Brasileira de Pesquisa de Trigo-2000. Cruz Alta, 2000. $90 \mathrm{p}$.

REIS, E.M. Manual de identificação e quantificação de doenças do trigo. Gráfica Estrela. Agroalpha, Passo Fundo. 1994. 59 p.

REIS, E.M., CASA, R.T. \& FORCELINI, C.A. Relação entre a severidade e a incidência da ferrugem da folha do trigo, causada por Puccinia triticina. Fitopatologia Brasileira 21:369-372. 1996.

REIS, E.M., CASA, R.T. \& FORCELINI, C.A. Doenças do trigo. In: Kimati, H., Amorim, L., Bergamin Filho, A., Camargo, L.E.A. \& Rezende, J.A.M. (Eds.) Manual de fitopatologia. Vol 2. Doenças das Plantas Cultivadas. 3. Ed. São Paulo SP. Ceres. 1997. pp. 725-735.

REIS, E.M., CASA, R.T., HOFFMANN, L.L. \& MENDES, C.M. Effect of leaf rust on wheat brain yield. Fitopatologia Brasileira 25:6771. 2000 .

REIS, E.M., CASA, R.T. \& MEDEIROS, C.A. Diagnose, patometria e controle de doenças de cereais de inverno. Londrina PR. MC Gráfica. 2001.

SAH, D.N. \& McKENZIE, D.R. Methods of generating different levels of disease epidemics in loss experiments. In: Teng, P.S. (Ed.) Crop loss assessment and pest management. Saint Paul MN. APS Press. 1987. pp. 90-95.

SAMBORSKY, D.J. Wheat leaf rust. In: Roelfs, A.P. \& Bushnell, W.R. (Eds.) The cereal rust: diseases, distribution, epidemiology, and control. Orlando FL. Academic Press. 1985. pp. 39-59.

TOMERLIN, J.R. \& HOWELL, T.A. DISTRAIN: a computer program for training people to estimate severity on cereal leaves. Plant Disease 72:455-459. 1988.

ZADOKS, J.C., CHANG, T.T. \& KONZAK, C.F. A decimal code for the growth stages of cereals. Cereal Rust Bulletin 3:14-23.1975. 